\title{
Double Duty: Crowdfunding and the Evolving Game Production Network
}

\author{
Heikki Tyni \\ School of Information Sciences \\ 33014 University of Tampere, Finland \\ heikki.tyni@uta.fi
}

\begin{abstract}
As independent game makers strive to tackle the demands of game production without the help of a traditional publisher, a familiar game production environment has started to evolve. Adopting a game production studies perspective, this article focuses on crowdfunding as a new channel for independent game development and the shifts crowdfunding causes in the game production network. Two successfully crowdfunded case examples - Bloodstained (2018), a digital game, and Conan (2016), a boardgame - are used to illustrate changes crowdfunding causes in the traditional game production environment. In removing the publisher as an "unnecessary" middle-man, crowdfunded productions need to take care of the many tasks that used to belong to publishers, such as marketing, partner sourcing, distribution networks, and customer relationships. As projects turn to emerging production network intermediaries, their significance - as well as that of the crowdfunding backers - provides evidence to classify the crowdfunding model as a new game production logic.
\end{abstract}




\section{Keywords}

Game industry, production networks, production studies, independent games, crowdfunding.

\section{INTRODUCTION}

Sidestepping the traditional role of the publisher in the games production value chain, games are now increasingly released as independent productions. This development has been accelerated mainly by the introduction of reliable digital distribution channels and the popularization of game platforms that focus exclusively on digitally distributed content (such as iOS and Android). Besides relying on self-financing, many of these independent productions seek financing through crowdfunding. In crowdfunding a project creator sets up a project for which they seek small funding contributions from a large group of individuals via the internet. Compared to traditional game publishing, where the publisher retains rights to the intellectual property (IP) associated with the game, crowdfunding provides developers with a seemingly ideal self-publishing channel, free from publisher influence.

The crowdfunding model has been examined predominantly in business and economic studies with focus on the possible factors behind campaign success (Mollick, 2014), determinants of backing behavior (Burtch, Ghose \& Wattal, 2014; Gerber \& Hui, 2013), creator motivations (Belleflamme, Lambert \& Schwienbacher, 2014; Gerber \& Hui, 2013), and the effects of location (Agrawal, Catalini \& Goldfarb, 2010), among others. The cultural phenomenon of games crowdfunding has been described in a few seminal articles (Smith, 2015; Planells, 2015), but to get deeper into the subject matter at hand academic research now needs more specific case studies exploring the crowdfunding environment.

This article is interested in the crowdfunding model as an alternative production environment for games. The main aim of the article is to map out the different parties associated with traditional 
game production, how this production network evolves with productions using the crowdfunding model and what kind of production logic can be applied to the crowdfunding production model. Drawing from Aphra Kerr (2017) and Jennifer Johns (2006), the analysis uses the concepts of production network and production logic. The article is equally interested in how this sub-sector of games production relates to the growth and restructuring of the games industry over the past decade and the political economy of the crowdfunding production environment, i.e. what consequences sidestepping the publisher via crowdfunding and digital distribution has for game developers. Digital distribution has been hailed as a liberator for independent game production, and popular rhetoric surrounding crowdfunding has envisioned it as the perfect tool for launching independent games. Using two successfully crowdfunded game productions - Bloodstained (2018) and Conan (2016) - as case examples, this article seeks to problematise these assumptions in detailing the different ways in which game crowdfunding is fast becoming a laborious affair with a new set of hindrances.

The article first discusses the theoretical background of the study, after which the method and data are elaborated. Following this, the "traditional" game production network (Johns, 2006) popular during the 1990s and early 2000s is outlined. Next, the key transformations shaping the game industry since the early 2000s are outlined and the emergence of crowdfunding production model is connected to this chain. The analysis section highlights the different ways in which the production network roles of crowdfunding are re-distributed to existing and new actors. Lastly, the conclusions section discusses the implications of the findings for wider game production research.

\section{THEORETICAL BACKGROUND AND RESEARCH QUESTIONS}

The theoretical basis of this study draws from the political economy of games and the production studies approach, emerged during the last decade, i.e. how cultural production is organised, how 
does this affect the produced cultural texts, who controls power and money within each system of production and how do these factors reflect on the cultural work force and the player communities (Kerr, 2017). During the first decade of the 2000s, critical analysis following this tradition was largely focused on the political economy of the traditional game industry, and the biggest blockbuster games (Nieborg, 2011; Kline, Dyer-Witheford \& de Peuter, 2003; Dyer-Witheford \& de Peuter, 2009; Kerr, 2006; Dymek, 2010), with focus on the centrality of platform owners and publishers as industry power brokers and on the ways developers were exploited in that production model. Since then, the introduction of digital distribution and the proliferation of mobile platforms have expanded and changed the game industry significantly. Research on the political economy of games has turned to mobile games as the most lucrative industry sector (Nieborg, 2016), while independent game production has grown significantly in numbers. While previous research focused mainly on the publisher/developer relationship, new axes have emerged, "including the developer/platform relationship, the developer/investor relationship and the developer/player relationship” (Kerr, 2017, 92). Emerging studies have concentrated on more nuanced matters, using for example industry ethnographies to detail how larger game industry shifts and specific production context affect and shape the everyday work of regular employees (O’Donnell, 2014; Jørgensen, 2017) and game design (de Smale, Kors \& Sandovar, 2017). Kerr argues that:

"[t]o understand the culture of gamework we need to pay attention to the range of actors (human and non-human) in game production networks, the differences in power between these actors and the experiences of workers both within the development companies and those external actors they engage with. Increasingly game production networks flow beyond firm boundaries and 
certain functions are outsourced (e.g. human resources, middleware, testing, marketing, community support, content creation). Little is known about the relationships generated and how they are managed.” $(2011,225)$

The most important of recent studies on the evolving game production environment, Global Games (Kerr, 2017), provides effective tools for the structural analysis of current and emerging game production models. Building on the works of Bernard Miège, Jean-Guy Lacroix and Gaëtan Tremblay, Kerr utilises the lens of production logic to illustrate and identify "the key market and institutional characteristics structuring different types of games production", focusing on the highlevel market conditions surrounding and shaping production (Kerr, 2017, 78). Further, she uses the lens of production network to give a nuanced understanding on what kind of network of actors typically runs a particular production logic and to highlight how value is created and who can capture this value (Kerr, 2017, 79). Through production networks, it is easier to understand at which point of the production lifecycle of game production different parties enter. While a production lifecycle was relatively simple in traditional publishing logic, it has evolved a lot, e.g. with the emergence of service-based gaming, new determinants for project success and new sources of project financing (Kerr, 2017, 87).

One of the new forms of financing is crowdfunding, increasingly used with independent game production. While there is an increasing body of critical cultural research on the state of independent games production (see e.g. Whitson, 2013; Lipkin, 2013), there are few critical studies that go deeper into crowdfunding as a production context for games. Picking up where Kerr (2017) left off, this study aims to illustrate the crowdfunding model as a new, branching production logic by exploring the production networks used with games crowdfunding. The aim here is to detail 
how game production in the crowdfunding model is organised around the central brokers, the economic chain and marketing concerns. Thus, the theoretical contribution of this study is to highlight the political economy of this particular game production model, i.e. the connections around the case crowdfunding campaigns, this way giving a better understanding of the related sub-sectoral industry structure, any emerging centers of power and who control that power, and possible instances of exploitation of work force or audience.

As these pressures reflect on the crowdfunding work environment, the article also connects to the increasing body of research concerned with media labour in the current network society, i.e. the evolving conditions and demands media workers find themselves dealing with. Baym (2015) describes how many artists working in creative industries are now required to engage in unsalaried social labour, meaning "regular, ongoing communication with audiences over time to build social relationships that foster paid work.” This kind of extra labour is now very much a demand also among independent game productions wishing to get noticed in a market based on social networks.

\section{METHODOLOGY AND DATA}

The main method of analysis adopts the concepts of production logic and production network (Kerr, 2017) to map out the rationale of the crowdfunding production environment. Kerr defines production logics as a "relatively stable set of institutional relationships generated by the commodification of cultural production” (2017, 15). Singling out general characteristics, the central brokers, the economic chain / network, creative professions, sales and revenue, and market characteristics, she identifies five main logics of cultural production within the current digital games industry (2017, 68-74): 
- Publishing logic - the classic game publishing logic, still mainly used with triple-A game production;

- Flow logic - a flow of content updates to keep players engaged, e.g. subscription based MMOGs;

- Club logic - a continuous service with an 'all-you-can-play' catalogue of content, based e.g. on monthly subscription;

- Performance logic - regular live events with performing gameplay to an audience as a source of revenue, e.g. through YouTube and Twitch or in tournaments;

- Platform logic - based on the central position of internet intermediaries, with equal importance placed on mobile devices, the continuous flow of data, algorithms and the free-to-play business model. Fast becoming the generic logic of the global game industry.

These logics are interweaving and influence each other and Kerr implies that the emerging production models can be explained with these logics or at least by combining elements from them (2017, 68, 78). Accordingly, in this article the crowdfunding model is examined as an emerging production logic that shares attributes with existing logics. Analysis details the production network of the crowdfunding model through two case games, detailing the relevant actors in the crowdfunding production logic and the dynamics between them. Crowdfunding gives indie development more structure compared to earlier, more free-form production. This more structured and transparent model with regular production updates offers research a new window on the intermediaries and the highs and lows of the production process as they happen. Examining the wider organisation of companies, suppliers, and "others who work to deliver a game" helps in understanding 1) who are the central brokers "setting the terms and conditions" for others to follow, 
and 2) why production is organised in a certain way, as dictated by the funding sources, the marketing environment and the central brokers (Kerr, 2017, 79, 81). As the crowdfunding model has been discussed using emancipatory rhetoric (Planells, 2015) it is important to gain a critical understanding of who is able to capture value in it. The concept of the production lifecycle is also given attention, as it helps to situate the different actors in a network and provides the examination with a chronological structure, i.e. what game productions need to do in each phase.

The analysis is illustrated with evidence from two example cases, Bloodstained: Ritual of the Night, a digital game, and Conan, a boardgame. Scheduled to release in 2018, Bloodstained: Ritual of the Night is a side-scrolling action adventure game. The crowdfunding campaign for Bloodstained was successfully completed in June 2015 with \$5,545,991 in pledges, then a record for digital games. It is set to release on all current generation game consoles. Bloodstained was conceived by the Japanese game developer Koji Igarashi who, having produced some of the most memorable instalments in the long running Castlevania series (Konami, 1986-2014), left Konami to create a spiritual Castlevania sequel of his own, affectively dubbed as "igavania”. Conan (Monolith, 2016) is a miniature boardgame based on the fantasy character Conan the Barbarian by Robert E. Howard. The game is played with highly detailed 30mm miniatures evoking classic fantasy boardgames such as HeroQuest (Milton Bradley \& Games Workshop, 1989). Crowdfunding campaign for Conan ended on February $12^{\text {th }}, 2015$, and gathered $\$ 3,327,467$ in pledges, then a record for boardgames.

Examining these games as case studies allows the data to consist of a "full variety of evidence" that can be combined with other data sets in flexible ways (Yin, 2009). With these example cases, this meant campaign and marketing material, update and announcement texts, interviews given to media, material on various social media including text and videos, and two-way communication 
on both the official campaign comments section and on popular hobbyist forums. Data was collected by the author during and after the campaigns in spring and summer 2015, but the observation continues until the expected release of Bloodstained. I was a backer on both campaigns, close-reading the campaign sites, updates, and other messaging on social media. I read most of the messaging on the official campaign comments section, paying attention particularly to any criticism by the users and the ways developers addressed these criticisms and other concerns. With Conan, I also followed the forums on the boardgaming site Boardgamegeek.com, widely regarded as the most significant boardgaming hobbyist site.

The two games were chosen as example cases for multiple reasons. First, I started to follow Conan by chance when the campaign had run for a few days. I backed the project to experience and observe first-hand the kind of high-profile campaign it seemed to evolve in to. I backed Bloodstained as I assumed it would come loaded with history and expectations from the fan community following its resemblance to the Castlevania games. Additionally, the campaign displayed captivating characteristics e.g. in gamifying the campaign marketing. Further, as both campaigns ended up having large and highly successful campaigns, they seemed to become large productions with a lot of intermediaries, highlighting the associated production networks.

The examination is limited to the high-profile forms of crowdfunding, i.e. the largest platform for creative projects, Kickstarter, and two highly successful projects. Further, as Kickstarter supports only reward based crowdfunding, other forms of crowdfunding such as patronage, loan and equity crowdfunding (see: Mollick, 2014) are excluded from this study.

\section{FROM TRADITIONAL PRODUCTION NETWORKS TO CROWDFUNDING}

From the 1980s up until the turn of the millennium, the games production network was largely based on the incremental value chain (Kline et al., 2003), comprised of platform holders, 
publishers, developers, distributors and retailers (Johns, 2006). A given production network might have also included such additional parties as venture capitalists and government agencies providing prototype funding (Kerr, 2006, 83). Of the video game retail value, the platform holder received 20\%, the developer and publisher 40\% (combined), the distributor 10\% and the retailer 30\% (Johns, 2006). Additionally, monetary connections tied the value chain parties together on different levels; the publisher for example also paid licensing fees to the platform holders, and the different parties jointly monetised marketing efforts (ibid.). Figure 1 showcases these interconnections within the production network. 


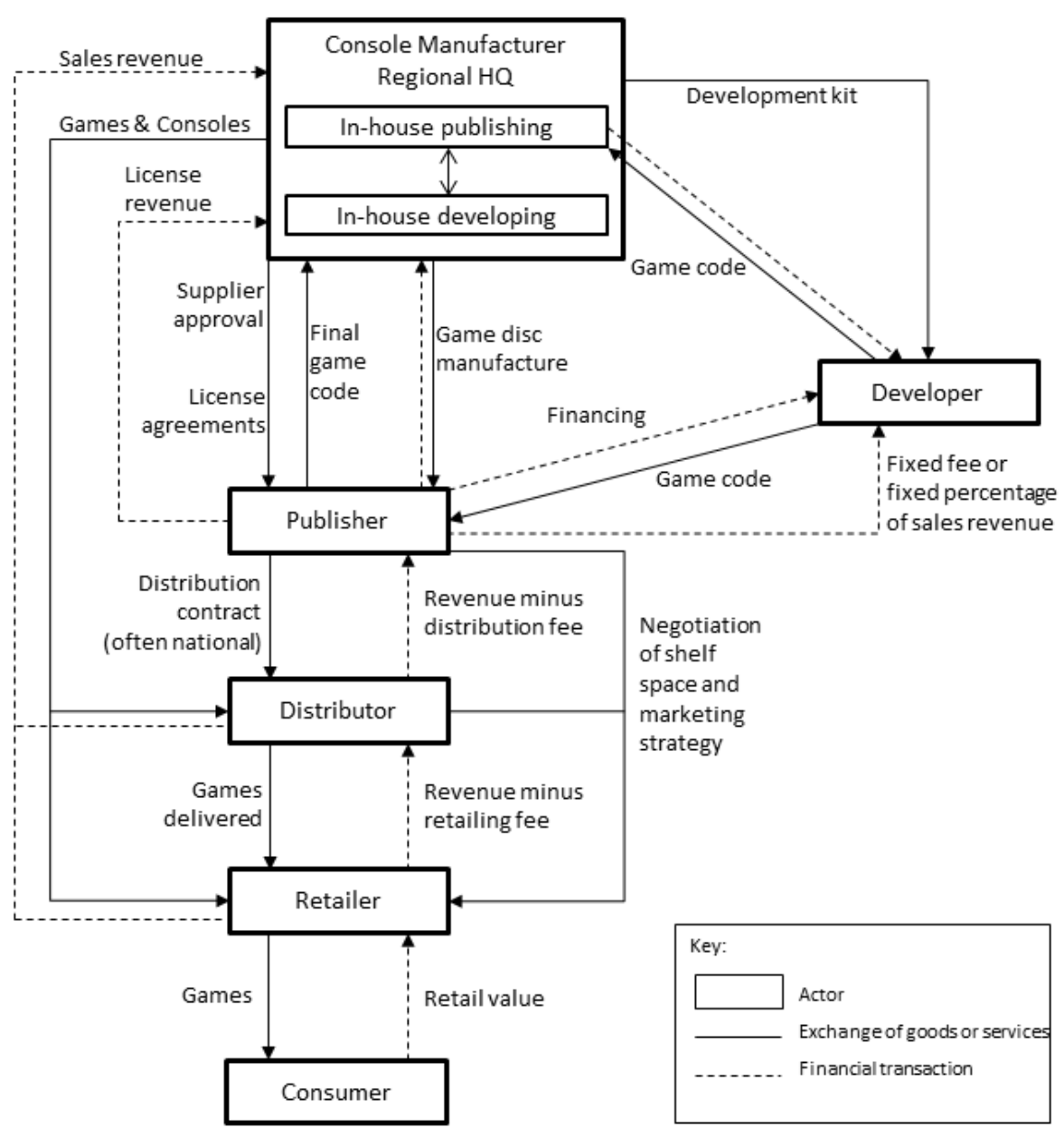

Figure 1. Interconnections between actors in the digital games production network (Johns, 2006)

The traditional production model is still largely in place for the biggest blockbusters, the socalled triple-A games, with the publisher as a central broker - or a "value chain governor" supervising production areas and controlling financing (Nieborg, 2011; Deuze, 2007). Publishers typically control projects’ core activities, while non-core services are outsourced (Grantham \& Kaplinsky, 2005, 199). As the publisher takes both the highest risk and the highest reward, its operating logic is dictated by the need to create sustainability (Kline et al., 2003). One solution to this has been constant increases in marketing expenditures: the largest publishers (EA, Activision, 
Ubisoft) direct roughly 50\% of their revenue into marketing (Zackariasson \& Wilson, 2012, 65). Many AAA-games have equal-sized marketing and development budgets (Kotaku, 2014), with the largest productions spending considerably more (Takahashi, 2009). Another strategy is vertical and horizontal industry integration which is used to increase control over the value chain and IP rights.

Publishers habitually demand the IP rights as a prerequisite for financing a game (Nieborg, 2011). In most cases the developer needs to showcase an advanced prototype of the game to secure a publishing deal; this has often resulted in the developer self-financing a prototype with a debt (Kerr, 2006, 81), then becoming obligated to agree to publisher's terms in order to secure financing that can be used to pay back that debt and start developing the game. In this traditional model, the profit share for the developer has remained around $10 \%$.

Since the turn of the millennium, the most notable techno-economic transitions shaping the game industry have been the introduction of online connected game consoles, digital distribution of games and the proliferation of game platforms. The largest revenues are now achieved in mobile instead of consoles (SuperData Research, 2015). Digital distribution platforms such as Valve’s Steam have helped introduce easy, reliable and fast plug-and-play gaming to increasingly wide audiences. Online connected consoles have allowed publishers to extend games through downloadable add-on content (Nieborg, 2014) and to maintain a continued service relationship with the player (Stenros \& Sotamaa, 2009), feeding them new content and promotions.

The service model has allowed publishers even more dominance over the value chain: digital distribution entirely sidesteps retail stores and physical distribution channels. Further, the material costs for manufacturing games are significantly lower. On the other hand, digital distribution has allowed developers to directly negotiate deals with platform holders, removing also the need for a publisher from the production chain (Sotamaa, Tyni, Toivonen, Malinen \& Rautio, 2011). Thus it 
would seem that digital distribution offers a more streamlined, efficient and direct model for selling digital games (see Figure 2 for a streamlined production network).

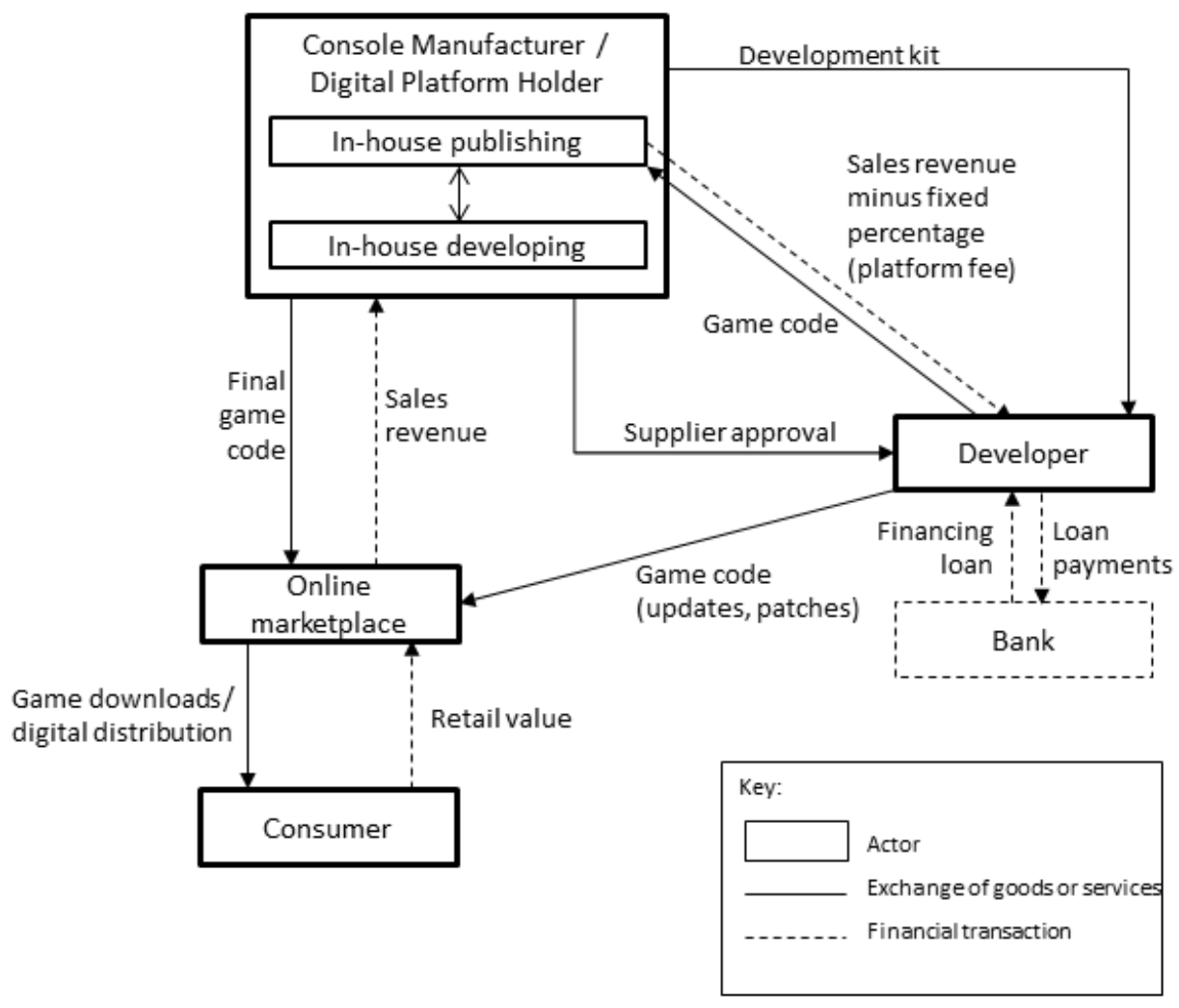

Figure 2. Streamlined production network for digital distribution

This new environment has helped the proliferation of independent games production. Due to the popularity of mobile platforms, small games created by teams of 1-5 people have the same kind of opportunity to become hits as AAA-games. With digital distribution, developers can receive up to $70 \%$ of the sales profits themselves (Sotamaa et al., 2011). For a developer, smaller games are easier to produce without incurring debt. While cultivating these niche audiences on a global scale can become lucrative business (Kline et al. 2003, 64), large publishers tend to look for the largest possible profit margins. Thus, one of the open possibilities for smaller developers has been to identify and address emerging niche audiences. 


\section{Towards crowdsourced and crowdfunded production logics}

Current independent game publishing is largely concentrated on digital PC storefronts and mobile app stores. Because of their popularity it is hard to get noticed on these platforms without promotional resources. One solution offered by Valve has been the creation of Steam Greenlight, a crowdsourcing platform used for peer-vetting user-created game concepts.

Crowdfunding platforms take this voting to its logical conclusion: users donate money upfront to micro-fund promising game concepts. In crowdfunding, a project creator sets up a project for which they seek small funding contributions from a large group of individuals via the internet. The project creator typically creates a pitch video in which they describe the game they would like to make, the skills and assets that prove they can actually execute the plan, and possible concept art, alpha footage or a prototype of the early version of the game. Funding is based on a tiered system: smallest steps, roughly $\$ 5-10$, typically yield a digital download of the game when it is completed, while higher tiers offer soundtracks, collector's editions, signed artwork, and so on. Project creators keep everything they receive on top of their minimum goal, with gradually rising 'stretch goals' used in describing how the project will use any extra funds.

The crowdfunding model provides developers with a financing channel that is seemingly free from publisher influence. In contrast to the traditional publishing model, where the publisher has typically kept developers and players far apart (Kerr, 2017, 71), many developers use crowdfunding as a means to address the gaming audience directly, asking gamers whether they would like to see the proposed game. As such, crowdfunding platforms are ideal channels for identifying and addressing niche game audiences. They have quickly become popular with game productions. Game crowdfunding has shown signs of plateauing in terms of money pledged, but the number of game projects seeking crowdfunding is increasing: in 2013, 4000 game projects were proposed on 
Kickstarter, while in 2016 the number was nearly 7000 (Bidaux, 2017). Consequently, it has become difficult to get noticed by the players and specialised media. Projects need to allocate more and more resources for an advanced working prototype, a high-quality campaign video, marketing and PR.

With crowdfunding and crowdsourcing platforms, the production of independent games has quickly moved towards a model that relies primarily on network markets (cf. Hartley, 2009), whether it is for getting visibility or funding. One consequence of such an environment is that developers now need to showcase a presentable prototype very early in the process in order to get a game published; not to secure a deal with a publisher, but to pre-sell the game to a large enough pool of individual funders, the 'crowd'. Financing a prototype might necessitate independent developers to seek other funding even before the crowdfunding period, while other marketing demands - before and during the funding period - frontload crowdfunded productions even further.

\section{ANALYSIS: RE-DISCOVERING PRODUCTION NETWORK ROLES}

A general challenge for smaller, independent game developers is the need to take care of every aspect of the production on their own. At the same time, crowdfunding campaigns have become increasingly professional in their quality, utilising a wide variety of marketing tactics. As such, independent game creators both need to take a financial risk in creating a prototype while also needing to prepare an impressive funding campaign, employing skills not traditionally associated with game development.

The following analysis focuses on the production lifecycle of two example games, Bloodstained and Conan, paying special attention to the different production network roles. The analysis is divided into sections concentrating on different areas of production, in loose chronological order. A special emphasis is placed on marketing resulting from its central role in 
the game industry in general (Marchand \& Hennig-Thurau, 2013; Zackariasson \& Wilson, 2012) and in the crowdfunding model in specific, explained above.

\section{Coordination and pre-campaign marketing}

Crowdfunding campaigns tend to follow a U-curve where the first and the last few days of the campaign are the most active and lucrative (Kuppuswamy \& Bayus, 2015). Pre-campaign marketing aims to build up the best possible start for a crowdfunding campaign. Creators need to start building anticipation and awareness of the upcoming game well in advance. Hui, Gerber and Greenberg (2012) concluded that campaign creators usually took 1-3 months to analyse the model for various opportunities and 3-6 months to prepare campaign materials. The most common explanation for failure given by unsuccessful project creators is that their marketing was inadequate (Mollick \& Kuppuswamy, 2014).

A closer look at the two projects reveals careful coordination behind their crowdfunding campaigns and subsequent production. The Conan campaign site listed 46 names involved in the project. Bloodstained was described as a "collaboration between dozens of people across a variety of companies”, with the campaign site introducing key people, guest artists and different “departments” such as 'PR', 'Pitch video' and 'Development'. Throughout the Bloodstained campaign an important partner for Igarashi was his translator and agent Ben Judd (of Digital Development Management (DDM)). Judd accompanied Igarashi for all his public appearances, often speaking for the relatively quiet Igarashi, adding to the translations and promoting the game. The campaign page listed “Coordination” and "Partner sourcing” as DDM's responsibility, while Judd called himself “campaign producer” (McDaniel, 2015). DDM secured most of the partners associated with the project, including the actual development studio, Inti Creates. Judd had earlier 
produced the very successful Kickstarter campaign of Mighty No. 9 (2016), another Japanese game based on a nostalgic genre.

The existence of Bloodstained was first teased in the fall 2014 PAX game conference with an unexplained “There Will Be Blood” flyer, including runic writing that fans later deciphered as: “What a wonderful night to have a KS“. Later, during spring 2015, a site called Swordorwhip.com appeared online featuring a caricature Igarashi sitting on a throne dressed as a vampire and asking “Sword or whip?” (both classic Castlevania weapon alternatives). Both answers prompted a request to "come back later", with other hints of an upcoming event starting to appear in the answers a week before the campaign. Igarashi and Judd started to make public appearances a few weeks prior to the campaign and final confirmation of the project was given on the day of the campaign launch.

The main video displayed on the campaign page is one of the most important elements of a crowdfunding campaign (Mollick, 2014). Kickstarter itself reports that "projects that have compelling videos tend to succeed at a much higher rate”. ${ }^{1}$ The main video for the Bloodstained campaign was handled by an independent video production studio called 2 Player Productions. The video, shot in a resort that resembles a gothic castle, featured Igarashi asking for funding for a spiritual sequel for the Castlevania games, while enacting scenes from his most famous games, eventually even turning into a bat. An independent merchandising company, Fangamer, was hired to handle most areas directly connected to PR and designing and running the Kickstarter campaign. The company also designed the merchandise mock-ups available on different reward tiers, the campaign page with a retro-game style castle that evolved as the campaign went along, and Swordorwhip.com. 
While a massively successful crowdfunding campaign no doubt acts as great promotion for an upcoming game, some developers are using the model more to prove that there is demand for a game, with additional funding coming from elsewhere (Handrahan, 2015; Fahey, 2014). This was true also with Bloodstained: Igarashi announced that the main reason for the campaign was to convince an undisclosed investor party who would provide main part of the funding in case the campaign was a success (the minimum requested by the campaign, $\$ 500,000$, was reported to be 10\% of the complete funding) (Nutt, 2015).

\section{Marketing during and after the campaign}

In game crowdfunding the public typically sees the game prototype for the first time when the campaign site goes live, meaning that the hardest marketing push starts from there. In supporting the campaign, projects typically use varying strategies to maintain interest, e.g. regular updates and reveals and different kinds of viral marketing. Among other variables, frequent project updates are associated with greater campaign success (Mollick, 2014). Crowdfunding platforms highly encourage projects to engaging social media during and around the campaign. ${ }^{2}$ During the Bloodstained campaign, major social media channels including Youtube, Facebook, Twitter, Tumblr, Instagram, Twitch and Vine were used to great effect. Besides backer updates, communication happened via Facebook, Twitter, weekly “Ask IGA” Youtube videos, and other channels. Igarashi and Judd gave interviews to gaming sites and toured several gaming shows and podcasts to market the game. Reddit was used for a live "ask me anything” session with Igarashi.

Bloodstained marketing and other processes were delegated also to funders through gamifying campaign activity. Gamification with a badge system, for example, has been shown to have a clear positive effect on user activity within a peer-to-peer system (Hamari, 2015). Fangamer used social media to gamify the campaign by creating special backer community "achievements" for the 
campaign. For example, the community could earn achievements when different social media channels achieved a certain number of followers and when enough fan art was posted online. A set number of achievements would then yield bonuses for the campaign, such as wallpapers and reveals of upcoming stretch goals. During the four-hour campaign ending live stream fans could make Igarashi shout classic lines from his games by tweeting them enough times and make him try to enact action moves from his games should the live stream become popular enough. Almost all of the achievements were unlocked, and the strategy no doubt worked to great effect both in harnessing the fan community to spread the word (i.e. viral marketing) and getting fans enthusiastic and engaged with the campaign.

Fan participation with the campaign worked also in other ways. During the Conan campaign, funders had endless questions about issues such as shipping, details about payment and release dates. This soon resulted in existing backers addressing many of the questions for newcomers, substituting for Monolith’s community manager when he was not available. Backers also openly discussed whether to spend more money on the project, or "up their pledge”. As all spending on the campaign works towards a larger game, benefitting all the funders, it is interesting to consider whether backers this way enticed each other to spend more money, resulting in herding behaviour (see e.g. Agrawal, Catalini \& Goldfarb, 2014). It is nevertheless clear that funders embrace crowdfunding projects as something more than a spectator: everybody involved is a stakeholder, whether it is about spending more money, enticing others to do so, or creating a more welcoming community for new funders.

To promote the Conan campaign, Monolith partnered with a few key partners. For its campaign video, Monolith used art assets from the MMORPG Age of Conan (Funcom, 2012), both games having been licensed by Paradox Entertainment. One stretch goal also included a cross- 
promotion with Age of Conan, where Conan backers would receive exclusive content to use in the MMORPG. Monolith also collaborated with CoolMiniOrNot, another boardgame publisher behind a string of successfully funded Kickstarter games, to create a shared scenario between Conan and Blood Rage (CoolMiniOrNot, 2015) with the ability to mix miniatures between the two games. Further, Monolith also collaborated with a (then in-development) pen-and-paper RPG, Robert E. Howard's Conan (Modiphius, 2016), allowing players to use Conan miniatures in roleplaying scenarios.

\section{Funding and payments}

In addition to paying possible fees to a gaming platform holder, crowdfunding projects need to pay fees to the crowdfunding platform. Kickstarter charges only successful projects - projects that meet their minimum goal -, taking a flat fee of $5 \%$ of the total funds collected. In the case of Bloodstained, the final Kickstarter fee was \$277,300, while Monolith paid \$166,373 for Conan. Kickstarter projects also pay a third party for payment transaction handling. Currently, this is handled by Stripe, whose fee varies by country and is between 3-5\% of the total funding amount. Bloodstained and Conan both were registered in the USA, where Stripe takes 3\% of each pledge plus $\$ 0.20$ per pledge.

The Bloodstained campaign also offered Paypal as an alternative payment option during the campaign. The final Kickstarter funding amount does not include funds pledged through PayPal, totaling over $\$ 213,000$. PayPal charges a fee based on the customer's country of origin; for Bloodstained the fee was 2.9\%-3.9\% + \$0.30 per pledge. Late backers could use PayPal also after the campaign: the so called "slacker backer" option was available through PayPal on Fangamer.com, the partner site who handled the Bloodstained campaign. Finally, projects with 
several possible reward tiers typically offer funders an opportunity to manage their pledge after the campaign, for example upgrading their reward tier to a more expensive one. Managing pledges with tens of thousands of funders this way might mean significant logistical challenges; thus, many large projects now pay an outside party for handling this part of the process. Post-campaign pledge management for Conan was handed to Fluent.com, while pledge management for Bloodstained was handled by Fangamer using their own software. O’Donnell (2014) has described how new game industry professions are often born to "fracture lines”. The emergence of pledge management services, for one, reflects the evolution of the crowdfunding model into a system with a value chain of its own.

In the traditional game production model the publisher handles most of the money issues using its established channels, but in the crowdfunding model the project creators need to create and maintain connections to multiple outside parties. Both projects needed to negotiate deals with several sub-contractors, both out of necessity and convenience. To create a Kickstarter project for the US platform, the project creator needs to have a US address. While Igarashi used Fangamer for this, Monolith had to use another boardgame company, Days of Wonder, as a proxy. This arrangement was not enough however, and to gain access to the successfully collected funds Monolith was eventually forced to set up a side office in the United States, with their production and delivery date delayed for half a year as a result.

Furthermore, while in the traditional production environment development studios operate primarily in a business-to-business environment (selling goods and services to the publisher), in the crowdfunding model the project creators are also in a direct relationship with the final customers: managing funds and refunds, solving problems related to failed transactions and means of payment, and so on. As a show of building trust, Monolith offered an extended two-month refund 
period for the Conan backers after the campaign. While this would have been enough of a task to deal with, the production faced delays; assuring disgruntled funders and trying to maintain positive atmosphere amidst production delays proved to be a continuous task for the company. Other problems included having to try to work out payment options for many of the Greek funders who, as a result of the Greek banking crisis, could not pay with credit cards, instead pleading for an option to pay with PayPal. With Bloodstained, on the other hand, customer and payment support in its entirety was outsourced to Fangamer.

\section{Development}

To make the projects possible, both game projects had to assemble a team of development professionals, either to directly work under them or to use as subcontractors. Already during the campaign phase, it was announced that Igarashi was employed by a mobile game company called ArtPlay and now heading its Japanese branch with Bloodstained development as their main focus. While Igarashi, through ArtPlay, was the producer of the project and a figurehead for the Bloodstained project, another Japanese development studio, Inti Creates, was hired to do the actual development process. Further, while the studio handled the development of the game for PC, PS4 and Xbox One, the project expanded significantly during the campaign: Wii U and PSVita ports were added through stretch goals. As a result, another studio, Armature, was contracted to develop them. In fall 2016 two more game studios, DICO and Monobit, were brought on to replace Inti Creates, as it lacked the necessary special skills Igarashi wanted. A company called Playism handled the campaign website translations and game text localisation, and also hosted marketing podcasts for the project.

Several content creators were brought in as highlighted collaborators during the campaign, many having ties either to Castlevania or Konami, including veteran Castlevania artists Ayami 
Kojima and Yoshitaka Amano, and the regular Castlevania composer Michiru Yamane. Voice work was handed to a studio called Rocketsound, with renowned voice artists (from Konami's past games) David Hayter and Robbie Belgrade to star in the game. These collaborators were revealed one-by-one during the campaign, this way evenly distributing the marketing value associated with them.

During the Bloodstained campaign, funders too had opportunities to influence the final design of the game - for a price. Fans could, for example, have themselves appear as portraits in the castle, make voice artists record them messages that would be hidden in the game code, have their pet turned into an in-game enemy and even design a weapon or a secret room in the game, with cost ranging from $\$ 750$ to $\$ 8500$. Altogether, 183 single rewards included some kind of opportunity to contribute to the in-game content, with almost all of them taken.

The main part of Conan's development was handled by Monolith, in Paris, France. Besides its own designers, artists, and sculptors, Monolith used a number of outside designers as subcontractors to create character art and sculpt miniature models. Among several freelancer designers, there were also highlighted visiting artists that contributed to different parts of the design process, including “Artist Boxes” with alternate character designs and three larger expansions for the game. Additional character art and models were also supplied by Funcom, with Monolith effectively reusing assets from Age of Conan MMORPG. Furthermore, Monolith chose to offer backers a digital companion app as one of their last stretch goals, something outside their core competency area in boardgames.

Conan too delegated a portion of the development process to the backers. During the campaign, it was announced that Monolith would create an online portal where players could produce their own play scenarios and campaigns. A prototype version of the game was sent to 
boardgaming clubs around the world; in return, each club would make a custom scenario for Monolith's online portal in time for the game's launch. Because Monolith advertised the online service - specifically, the vast number of additional scenarios - as a part of the complete experience, fans directly participated in Conan's creation, similar to how modding communities are welcomed into co-creating digital games (see e.g. Banks, 2013). A print-and-play prototype of the game was also released during the campaign with the encouragement that any "bugs" in the design would be reported back to Monolith. This way, the backer community acted as a final gameplay stress test for the game.

While previous research has seen fit to draw clear boundaries between crowdsourced work and crowdfunding (e.g. Brabham, 2013; Hui et al., 2012), it is evident that the line between the two is liable to become increasingly blurred. Both Conan and Bloodstained employed a strategy of utilising supporters as work force, Bloodstained more with marketing and Conan primarily with development efforts. Banks and Humphreys (2008) have argued that this kind of value-adding labour by user co-creators forms new kinds of "hybrid relations that cut across the commercial and non-commercial social networks and markets" and that while "messy", these "new formations hold a wide range of benefits and value.” The multifaceted contributions of crowdfunding backers are clearly worth a lot and can be seen tightly intertwining with the actual monetary contributions for the campaign.

\section{Manufacturing and distribution}

Resulting from a structure based on gradually increasing stretch goals, massively successful crowdfunding campaigns can result in significantly expanded projects. As with development, both Conan and Bloodstained also needed to select and collaborate with several partners in various stages of production. Studies have reported that crowdfunding campaign creators are often 
overwhelmed by executing and delivering a product on a much larger scale compared to their prior experience, and as a result have turned to outsourced help (Hui et al., 2012; Agrawal et al., 2014). During the final days of the Conan campaign, Monolith struggled to keep up with the fast campaign progress; new stretch goal characters, for example, were announced without concept art.

A constant source of worry for the backers during and after the Conan campaign was the quality of figurine production. Because of the varying quality of the contractors, choosing production partners from China is challenging for both startups and veteran developers. Monolith partnered with Dust Studios (headed by one of the visiting artists on the project) to handle transporting the sculpt designs into mass production. Conan miniatures were manufactured in China by the same manufacturer Dust Studios had previously used for their own projects. Even this could not prevent further delays in the production process: mainly due to Chinese New Year period the delivery of the figurines was eventually delayed for another six months.

Information regarding how much Monolith would have to charge for shipping Conan changed a few times, causing anguish among the backers. Veteran backers already knew that distribution is often expensive, but many were still disappointed to find out that shipping for some territories exceeded $\$ 50$. While digital games can be distributed in digital-only form, many projects include physical rewards, especially on the higher funding tiers. Among other rewards, the Bloodstained campaign offered a physical game box, a soundtrack CD, a retro strategy booklet, an art book and an XL-sized physical map, along with the more traditional T-shirts, posters, and lapel pins. Fangamer handled the physical rewards using their established connections to commission the manufacturing and shipping for different subcontractors. Finally, as a digital game scheduled also for a physical release, Bloodstained needed to pay the console platform holders for producing physical copies of the game. 


\section{Results summary: Crowdfunding as a branching production logic}

Looking at the production networks of the example games we can see that in wanting to remove the publisher from the network, the developers need to shoulder many new responsibilities previously associated with the publisher. O’Donnell (2014) describes how shifting requirements in the game industry have necessitated re-organising the production structure through creating new industry professions. Instead of getting rid of the roles formerly associated with the publisher, the roles were redistributed (in some cases in fragmented form) to existing and new parties in the production network. The need for marketing has risen all the time, and evidence from the example cases suggests that independent game development projects become increasingly frontloaded with preparation work. Much of this work falls outside of the traditional core competency of game developers.

Both example projects needed to secure a lot of intermediary connections; Igarashi even hired a company to coordinate them. Figure 3. showcases the emerging production network actors involved with the crowdfunding model. The example campaigns were successful because the developers adopted a decidedly "publisherly" role, both out of necessity and as a strategy. Additionally, the crowdfunding platform emerges as a "neutral" central broker - comparable to a social network platform -, which nevertheless dictates the rules, sets the marketing stage and has significant control over visibility. 


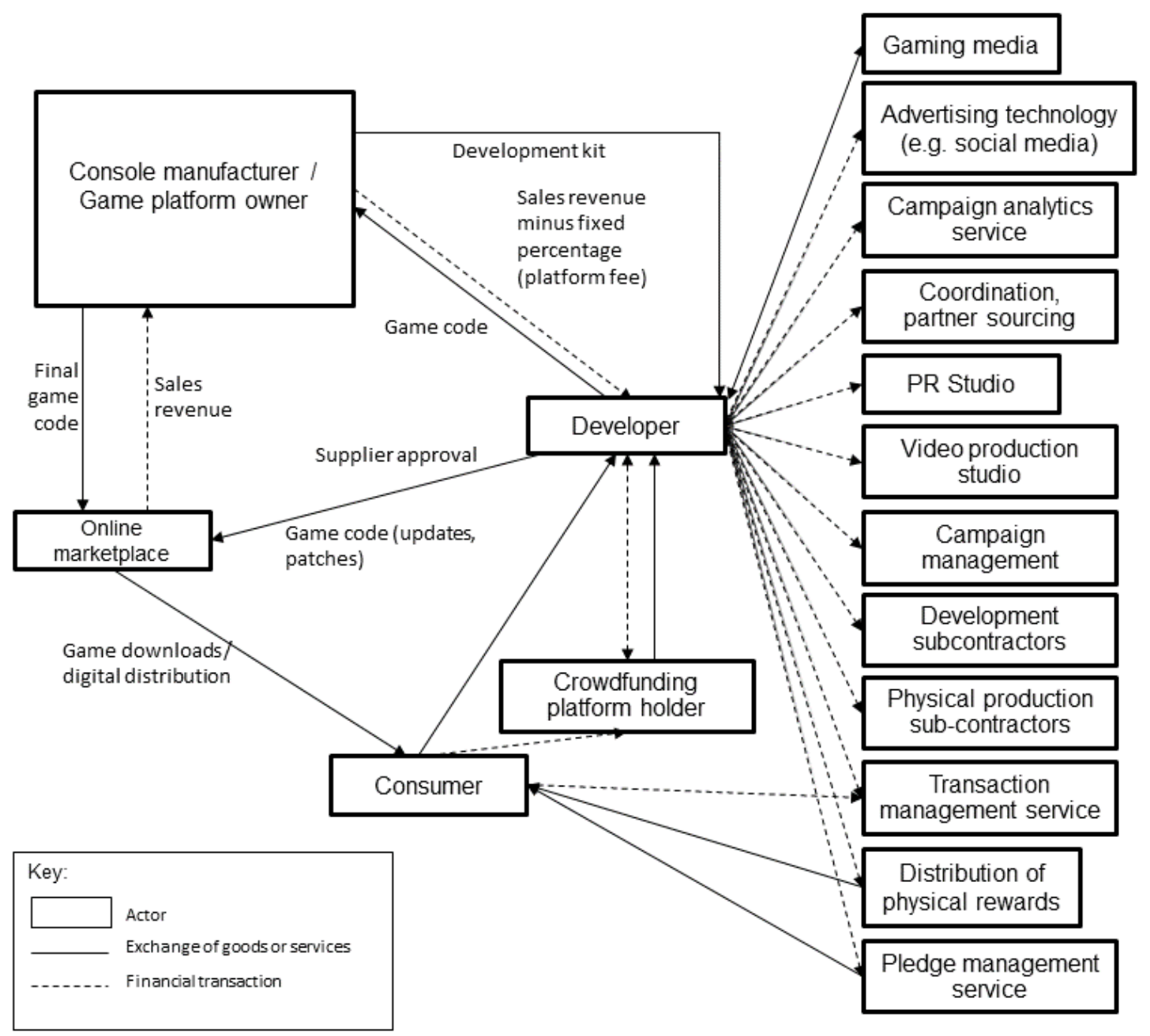

Figure 3. Example production network in the crowdfunding model

When we turn to the concept of production logics and place the crowdfunding model next to its closest comparison points, the classic publishing and flow logics (see Table 1.), we can see that it is mainly a combination of classic publishing logic mixed with the more modern tendencies of platform logic. The unusually strong top-heaviness of the production project illustrates some of the more general tendencies of current game production, i.e. a strong emphasis on marketing and what it demands. However, there are also characteristics separate from the existing logics, mainly the 
role of customers/backers as central brokers. They must be negotiated with, at least in the campaign phase.

\begin{tabular}{|c|c|c|c|}
\hline Characteristics & Publishing & Platform & Crowdfunding \\
\hline General & $\begin{array}{l}\text { One-off cultural } \\
\text { commodities, impulse } \\
\text { purchases }\end{array}$ & $\begin{array}{l}\text { Continuous flow of user data, } \\
\text { prof. and amateur created } \\
\text { content, content } \\
\text { personalization and } \\
\text { adaptation }\end{array}$ & $\begin{array}{l}\text { Pre-publication grass-roots market, } \\
\text { a semi-live service and semi- } \\
\text { continuous flow of content during } \\
\text { campaign, one-off cultural } \\
\text { commodities, impulse purchases, } \\
\text { collecting funding before the } \\
\text { product has been created, } \\
\text { maintaining a regular service after } \\
\text { the campaign }\end{array}$ \\
\hline Central broker & $\begin{array}{l}\text { Publishers, } \\
\text { platforms/publishers }\end{array}$ & $\begin{array}{l}\text { Platform } \\
\text { intermediaries/developers/ } \\
\text { publishers }\end{array}$ & $\begin{array}{l}\text { Platform intermediaries, } \\
\text { developers, backers }\end{array}$ \\
\hline $\begin{array}{l}\text { Economic chain / } \\
\text { network }\end{array}$ & $\begin{array}{l}\text { Project by project basis, } \\
\text { irregular work, royalties } \\
\text { and copyright }\end{array}$ & $\begin{array}{l}\text { Project by project basis, } \\
\text { Programmers, engineers, data } \\
\text { analysts, customer relations } \\
\text { and support } \\
\text { Wage and freelance labour } \\
\text { but also amateurs }\end{array}$ & $\begin{array}{l}\text { Project by project basis, Freelance } \\
\text { and amateur labour; Customer } \\
\text { relations }\end{array}$ \\
\hline $\begin{array}{l}\text { Creative } \\
\text { professions }\end{array}$ & $\begin{array}{l}\text { Authors, composers, } \\
\text { directors, artists and } \\
\text { specialized technicians }\end{array}$ & $\begin{array}{l}\text { Designers, artists, engineers, } \\
\text { network support, marketing, } \\
\text { data analysts, community } \\
\text { managers, game designers, } \\
\text { players }\end{array}$ & $\begin{array}{l}\text { Designers, programmers, artists, } \\
\text { marketing, logistics personnel, } \\
\text { community managers, players }\end{array}$ \\
\hline Sales \& revenue & $\begin{array}{l}\text { Direct } \\
\text { Product by product } \\
\text { Premium }\end{array}$ & $\begin{array}{l}\text { Indirect - freemium } \\
\text { advertising, data. Some direct } \\
\text {-DLC, micro-transactions }\end{array}$ & $\begin{array}{l}\text { Direct - Pre-launch sales, product } \\
\text { by product, pledges in tiered } \\
\text { options, Product to be delivered } \\
\text { later, Major part of profit from } \\
\text { post-launch sales }\end{array}$ \\
\hline $\begin{array}{l}\text { Market } \\
\text { characteristics }\end{array}$ & $\begin{array}{l}\text { Segmented mass market, } \\
\text { catalogue }\end{array}$ & $\begin{array}{l}\text { Niche, fragmented, } \\
\text { personalised }\end{array}$ & $\begin{array}{l}\text { Niche market, some } \\
\text { personalisation }\end{array}$ \\
\hline
\end{tabular}

Table 1. Example logics of cultural production in game industry compared with the crowdfunding model (Kerr, 2017; adapted) 


\section{DISCUSSION AND CONCLUSIONS}

Through two example cases, this study has highlighted the position of the independent game developer in the larger production network. Game crowdfunding is a highly competetive area that lies at the crossroads of marketing, game development and grass-roots user engagement. As a result of resorting to crowdfunding, game studios need to engage in several kinds of production efforts that lie outside of the traditional core of game development. This means both learning new skills often on-the-go - and having to spend increasing amounts of time on tasks like PR, customer service and negotiating with manufacturing partners. This, in turn, has led to a need to resort to external help e.g. to handle campaign logistics or hiring new community management personnel. Often this means that the studio needs to keep its fan community "entertained" for $2+$ years, corresponding with the observations by Baym (2015). As a large part of the marketing is done at the grassroots level, facing the audience almost one-on-one, it could be argued that every individual associated with the project does marketing (e.g. spreading the word and giving a trustworthy, human face to the project). All of this highlights how the core of game development, also for crowdfunded independent games, has shifted away from making the game and towards promotion and marketing, a development that draws comparisons to the development of F2P games and their move towards metrics (Kerr, 2017, 91).

Crowdfunding offers a good example of how the production lifecycle of independent games has evolved during the last decade. Some projects, for example, see gaining publicity and a player community as their most important goal. The chronology of the lifecycle has changed too: building a polished prototype, continuous marketing, financing and direct customer service, all need to be considered much earlier in the production cycle than previously. Despite these hardships, many successful crowdfunding projects now manage to avoid the need to take large loans to finance the 
development period, and in turn can keep the rights to the developed IP. One implication of this kind of development might be the emergence of a new kind of developer-publisher relationship. Instead of being the central broker in the production network, smaller publishers such as 505 Games might be content with being "equal” partners, helping with marketing and visibility and taking care of distribution - leaving the developer more time for actual development. Additionally, as developers become more open about the collaborators they use, small-scale intermediaries are able to get more visibility.

The crowdfunding model is a result of increasing globalisation and the consecutive networking of markets and user communities. It is positioned between emerging participatory culture practices and the commercial powers that seek to appropriate and harness these practices. While the model has the potential to be a more emancipatory and democratic area of cultural production, this article has tried to highlight how it has become more and more saturated with market mechanisms moving in from more traditional production logics. The implication is not necessarily that these commercial logics slowly seek to commoditize cultural production - although that too can be argued - but that the crowdfunding model constitutes one of the new forms of "hybrid relations that cut across the commercial and non-commercial social networks and markets” and that the true value of these relations remains to be seen (Banks \& Humphreys, 2008, 402). Different kinds of dual roles illustrate the blurring of lines between production roles in social network markets, but also serve as an example of how everywhere in the contemporary global economy fewer resources are expected to produce more. Furthermore, the crowdfunding model highlights how the element of risk moves downwards within cultural production: by taking the publishing duties into their own hands, independent game developers move the risk onto themselves and through crowdfunding this risk is then moved partly or entirely to the player-users. 
Further research is needed on the conditions of independent game production and how games crowdfunding affects and shapes both the possibilities of game makers and the resulting cultural texts. Additionally, more studies are needed on how the crowdfunding model itself evolves - as a tool and a platform -, as more commercial forces find it and find new and possibly more effective ways to use it, and as future policies shape it.

\section{REFERENCES}

Agrawal, A. K., Catalini, C., \& Goldfarb, A. (2010). The geography of crowdfunding. SSRN Electronic Journal, Social Science Research Network. Rochester, NY.

Agrawal, A. K., Catalini, C., \& Goldfarb, A. (2014). Some simple economics of crowdfunding. Innovation Policy and the Economy, 14(1), 63-97.

Banks, J. (2013). Co-creating videogames. Bloomsbury Publishing.

Banks, J., \& Humphreys, S. (2008). The labour of user co-creators: Emergent social network markets? Convergence, 14(4), 401-418.

Baym, N. K. (2015). Connect with your audience!: The relational labor of connection. The Communication Review, Special Issue, 18(1), 14-22.

Belleflamme, P., Lambert, T., \& Schwienbacher, A. (2014). Crowdfunding: Tapping the right crowd. Journal of business venturing, 29(5), 585-609.

Bidaux, T. (2017). Kickstarter and Games - 2017 mid-year status update. ICO Partners. Retrieved from http://icopartners.com/2017/07/kickstarter-and-games-2017-mid-yearstatus-update/

Brabham, D. (2013). Crowdsourcing. The MIT Press, Cambridge \& London. 
Burtch, G., Ghose, A., \& Wattal, S. (2014). An empirical examination of peer referrals in online crowdfunding. In Proceedings of $35^{\text {th }}$ International Conference on Information Systems, Auckland 2014.

de Smale, S., Kors, M., \& Sandovar, A. (2017). The case of This War of Mine: A production studies perspective on moral game design. Games and Culture. First published online Aug. 29, 2017. doi: 10.1177/1555412017725996.

Deuze, M. (2007). Media work. Polity.

Dyer-Witheford, N. \& de Peuter, G. (2009). Games of empire. University of Minnesota Press, Minneapolis.

Dymek, M. (2010). Industrial phantasmagoria: Subcultural interactive cinema meets masscultural media of simulation. Royal Institute of Technology, Stockholm.

Fahey, R. (2014). Kickstarter can't just be funding for newcomers. Gameindustry.biz. May $23^{\text {th }}$ 2014. Retrieved from: http://www.gamesindustry.biz/articles/2014-05-22-kickstartercant-just-be-funding-for-newcomers

Gerber, E. M., \& Hui, J. (2013). Crowdfunding: Motivations and deterrents for participation. ACM Transactions on Computer-Human Interaction (TOCHI), 20(6), 34.

Grantham, A. \& Kaplinsky, R. (2005). Getting the measure of the electronic games industry: developers and the management of innovation. International Journal of Innovation Management, 9(02), 183-213.

Hamari, J. (2015). Do badges increase user activity? A field experiment on the effects of gamification. Computers in Human Behavior. doi:10.1016/j.chb.2015.03.036 
Handrahan, M. (2015). Shenmue 3 breaks Kickstarter video game record. Gameindustry.biz. Jul

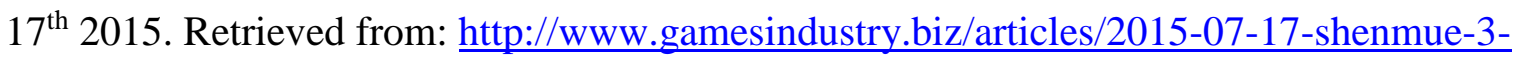
breaks-kickstarter-video-game-record

Hartley, J. (2009). Media industry studies: All change? In J. Holt \& Perren, A. (eds.) Media industries: History, theory, and method. Malden, Wiley-Blackwell.

Hui, J. S., Gerber, E., \& Greenberg, M. (2012). Easy money? The demands of crowdfunding work. Segal Design Institute, Technical Report No. 4.

Johns, J. (2006). Video game production networks: Value capture, power relations and embeddedness. Journal of Economic Geography, 6(2), 151-180.

Jørgensen, K. (2017). Newcomers in a global industry: Challenges of a Norwegian game company. Games and Culture. First published online Aug. $2^{\text {nd }}$, 2017. doi:

$10.1177 / 1555412017723265$

Kerr, A. (2006). The business and culture of digital games: Gamework/gameplay. Sage, London.

Kerr, A. (2011). The culture of gamework. In M. Deuze (ed.) Managing media work, 225-236. Sage, London, Thousand Oaks \& New Delhi.

Kerr, A. (2017). Global games: Production, circulation and policy in the networked era. Routledge, New York \& London.

Kline, S., Dyer-Witheford, N., \& de Peuter, G. (2003). Digital play: The interaction of technology, culture, and marketing. McGill-Queen’s University Press, Montreal \& Kingston, London and Ithaca.

Kotaku.com (2014). How much does it cost to make a big video game? Kotaku.com. Retrieved from: http://kotaku.com/how-much-does-it-cost-to-make-a-big-video-game-1501413649 
Kuppuswamy, V. \& Bayus, B. (2015). Crowdfunding creative ideas: The dynamics of project backers in Kickstarter. UNC Kenan-Flagler Research Paper No. 2013-15. Retrieved from: http://ssrn.com/abstract=2234765

Lipkin, N. (2013). Examining indie's independence: The meaning of "indie" games, the politics of production, and mainstream cooptation. Loading..., 7(11), 8-24.

Marchand, A. \& Hennig-Thurau, T. (2013). Value creation in the video game industry: Industry economics, consumer benefits, and research opportunities. Journal of Interactive Marketing, 27(3), 141-157.

McDonald, M. (2015). Bloodstained Community Broadcast Episode 2 - Halloween with Ben Judd. Bloodstained Community Broadcast. Retrieved from: https://www.youtube.com/watch?v=GPz_Wq5IZVc

Mollick, E. (2014). The dynamics of crowdfunding: An exploratory study. Journal of Business Venturing, 29(1), 1-16.

Mollick, E. \& Kuppuswamy, V. (2014). After the campaign: Outcomes of crowdfunding. UNC Kenan-Flagler Research Paper No. 2376997. Retrieved from: http://ssrn.com/abstract=2376997

Nieborg, D. (2011). Triple-A: The political economy of the blockbuster video game. University of Amsterdam.

Nieborg, D. (2014). Prolonging the magic: The political economy of the 7th generation console game. Eludamos - Journal for Computer Game Culture, 8(1), 47-63.

Nieborg, D. (2016). From premium to freemium: The political economy of the app. In M. Willson \& Leaver, T. (eds.) Social, Casual and Mobile Games: The Changing Gaming Landscape, 225-240. 
Nutt, C. (2015). Q\&A: Castlevania's Koji Igarashi returns with new game, Bloodstained.

Gamasutra.com. May $11^{\text {th }}$ 2015. Retrieved from:

http://www.gamasutra.com/view/news/243131/QA_Castlevanias_Koji_Igarashi_returns

with_new_game_Bloodstained.php

O’Donnell, C. (2014). Developer’s dilemma. The MIT Press, Cambridge, Mass.

Planells, A. J. (2015). Video games and the crowdfunding ideology: From the gamer-buyer to the prosumer-investor. Journal of Consumer Culture. First published online Oct. $18^{\text {th }} 2015$. doi: $10.1177 / 1469540515611200$

Smith, A. N. (2015). The backer-developer connection: Exploring crowdfunding's influence on video game production. New Media and Society, 17(2), 198-214.

Sotamaa, O., Tyni, H., Toivonen, S., Malinen, T., \& Rautio, E. (2011). New paradigms for digital games: The Finnish perspective, Future Play project, final report. TRIM research reports 3. University of Tampere, Tampere.

Stenros, J. \& Sotamaa, O. (2009). Commoditization of helping players play: Rise of the service paradigm. In Proceedings of DiGRA 2009 Conference. Brunel University, London.

SuperData Research. (2015). Global Games Market Report May2015. SuperData Research.

Retrieved from: http://superdata-research.myshopify.com/products/global-games-marketreport-may2015

Takahashi, D. (2009). EA's chief creative officer describes game industry's re-engineering. VentureBeat. Aug. 26 ${ }^{\text {th }}$ 2009. Retrieved from: http://venturebeat.com/2009/08/26/easchief-creative-officer-describes-game-industrys-re-engineering/

Whitson, J. (2013). The 'console ship is sinking' and what this means for indies. Loading..., 7(11), 122-129. 
Yin, R.K. (2009). Case study research: Design and methods. (4.ed.) Sage, Los Angeles, London, New Delhi, Singapore \& Washington DC.

Zackariasson, P. \& Wilson, T. L. (2012). Marketing of video games. In P. Zackariasson \& Wilson, T. L. (eds.) The video game industry, 55-75. Routledge, New York \& London.

\section{ENDNOTES}

${ }^{1}$ https://www.kickstarter.com/help/faq/creator+questions

${ }^{2}$ See e.g.: https://www.rockethub.com/education/faq\#use-social-media 